\title{
Developing a Canadian emergency medical services research agenda: a baseline study of stakeholder opinions
}

\author{
Katie N. Dainty, PhD*; Jan L. Jensen, MAHSR, ACP ${ }^{\dagger}$; Blair L. Bigham, MSc, ACP ${ }^{\ddagger}$; \\ Ian E. Blanchard, MSc, EMT-P§; Lawrence H. Brown, PhD, MPH\&TM, EMT-P"; \\ Alix J.E. Carter, MD, MPH ${ }^{\dagger}$; Doug Socha, BSc, PCP ; Laurie J. Morrison, MD, MSc* \\ ABSTRACT

\section{RÉSUMÉ}

Purpose: This study forms the first phase in the development of the Canadian National EMS Research Agenda. The purpose was to understand the current state of emergency medical services (EMS) research through the barriers and opportunities perceived by key stakeholders in the Canadian system and to identify the recommendations this group had for moving forward.

Methods: This qualitative study was conducted in the spring of 2011 using one-on-one semistructured telephone interviews. Purposeful sampling was used to recruit a cross section of EMS research stakeholders, representing a breadth of geographic regions and roles. Data were collected until thematic saturation was reached. A constant comparative approach was used to develop a basic coding framework and identify emerging themes.

Results: Twenty stakeholders were invited to participate, and saturation was reached after 13 interviews. Thematic saturation was used to ensure that the findings were grounded in the data. Four major themes were identified: 1) the need for additional research education within EMS; 2 ) the importance of creating an infrastructure to support pan-Canadian research collaboration; 3) addressing the complexities of involving EMS providers in research; and 4) considerations for a national research agenda.

Conclusion: This hypothesis-generating study reveals key areas regarding EMS research in Canada and through the guidance it provides is a first step in the development of a comprehensive national research agenda. Our intention is to collate the identified themes with the results of a larger roundtable discussion and Delphi survey and, in doing so, guide development of a Canadian national EMS research agenda.
But: L'étude décrite ici constitue la première étape de l'élaboration d'un programme canadien de recherche sur les services médicaux d'urgence. Elle avait pour buts de faire état de la situation actuelle de la recherche sur les services médicaux d'urgence (SMU) sous l'angle des obstacles et des possibilités tels qu'ils sont perçus par les principaux intervenants dans le système canadien, et de dégager les recommandations du groupe pour aller de l'avant.

Méthode: Cette étude qualitative a été menée au cours du printemps de 2011 à l'aide d'entrevues téléphoniques individuelles, semi-structurées. Nous nous sommes appuyés sur un échantillon choisi à dessein pour obtenir un sousensemble transversal des différents intervenants en recherche sur les SMU, représentatif des régions et des rôles. II y a eu collecte de données jusqu'à l'atteinte d'une saturation thématique. Nous avons appliqué une méthode comparative constante afin d'élaborer un cadre de codage de base et de dégager les principaux thèmes.

Résultats: Vingt intervenants ont été invités à participer au projet, et il y a eu atteinte du point de saturation après 13 entrevues. La recherche de la saturation thématique visait à ancrer les résultats de l'exercice dans les données. II s'est dégagé quatre grands thèmes: 1) le besoin de formation supplémentaire en recherche dans le domaine des SMU; 2) l'importance de mettre sur pied une infrastructure visant à favoriser une collaboration pancanadienne en matière de recherche; 3) les moyens de surmonter les difficultés à faire participer les fournisseurs de SMU à la recherche; et 4) différents aspects à envisager dans l'élaboration d'un programme national de recherche.

Conclusions: Cette étude exploratoire a fait ressortir des domaines importants en ce qui concerne la recherche en matière de SMU au Canada, et, par I'orientation qu'elle

From * Rescu, Li Ka Shing Knowledge Institute, St. Michael's Hospital, University of Toronto, Toronto, ON; †Emergency Health Services, Division of EMS, Dalhousie University, Halifax, NS; †Rescu, York Region Emergency Medical Services, Sharon, ON; §Alberta Health Services EMS, Department of Community Health Sciences, Faculty of Medicine, University of Calgary, Calgary AB; ॥School of Public Health, Tropical Medicine and Rehabilitation Sciences, James Cook University, Queensland, Australia; $\uparrow$ Rescu, Hastings-Quinte EMS, Hastings County, ON.

Correspondence to: Jan L. Jensen, 239 Brownlow Avenue, Suite 300, Dartmouth, NS B3B 2B2; jljensen@dal.ca.

This article has been peer reviewed.

(c) Canadian Association of Emergency Physicians 
imprime, elle constitue la première étape de l'élaboration d'un programme national et global de recherche. Nous avons l'intention de mettre en commun les différents thèmes qui se sont dégagés de l'étude et les résultats d'une table ronde et d'une enquête menée selon la méthode Delphi, d'une taille plus grande que celle ici décrite, et, ainsi, d'aiguiller l'élaboration d'un programme canadien de recherche sur les SMU.

Keywords: emergency medical services, qualitative, research, research agenda
Research related to emergency medical services (EMS) has been increasingly recognized as an essential component of the Canadian EMS framework by national groups, including the EMS Chiefs of Canada (EMSCC), ${ }^{1}$ the Paramedic Association of Canada (PAC), and the Canadian Association of Emergency Physicians-EMS Committee (CAEP-EMS). Despite this, relatively little is empirically known about the current state of EMS research in Canada. Questions regarding strengths, issues of concern, areas of focus for future research, and recommendations for moving forward have never been systematically addressed on a national level. Moreover, although some areas in Canada produce a large volume of high-quality EMS research, others conduct little or no EMS research, and to date there have been no studies on how to improve this.

The Canadian National EMS Research Agenda project $^{2}$ was initiated to bring stakeholders together to develop key messages intended to guide the strategic direction and strength of the Canadian EMS research enterprise. The project has three phases: phase 1, qualitative baseline interviews; phase 2, an in-person roundtable session; and phase 3 , an online multiround Delphi consensus survey.

The first phase, reported here, was designed to investigate the perceptions and experiences of various individuals involved in Canadian EMS research. The primary purpose was to elicit themes that could serve as a broad sampling of the national perspective and to initiate discussion at the subsequent in-person roundtable. More specifically, we sought to understand the current state of EMS research through the barriers and opportunities perceived by key stakeholders in the Canadian system and to identify the recommendations this group had for moving forward.

\section{METHODS}

This qualitative study was conducted through one-onone semistructured interviews with key informants. Research ethics approval was received from St. Michael's Hospital, Toronto.

\section{Sample}

Investigators identified stakeholder groups to be invited to participate in the EMS Research Agenda project (Table 1). Based on knowledge of the Canadian EMS community, a list of individuals representing these key groups was generated by the study team. Potential participants were tentatively assigned to the stakeholder group that best described their activities, and participants later had the opportunity to selfidentify their most appropriate group at the time of the interview and, if necessary, be reclassified for the final results. For this baseline qualitative phase of the project, a purposeful sample of three to four representatives per stakeholder group was selected for telephone interview. Geographic location and relevant organizational representation were considered when selections were made within each stakeholder group in an effort to obtain a representative sample. ${ }^{3}$

\section{Sampling approach}

In February 2011, potential participants were emailed an invitation letter to participate in all phases of the Canadian National EMS Research Agenda project. A sample of those who agreed to participate was subsequently selected for this phase and sent a second email explaining the baseline qualitative study in greater detail and requesting an interview. Invitees who were willing to participate in the baseline study were asked to reply to the lead investigator (K.N.D.) via email. A letter of information and consent was then sent in reply, along with an interview appointment. The sampling methods for the other project phases will be reported elsewhere.

\section{Informed consent and data collection}

At the time of the interview, the researcher confirmed that the participant had received the information package, reminded them that participation was voluntary, and obtained verbal consent. Interviews were 


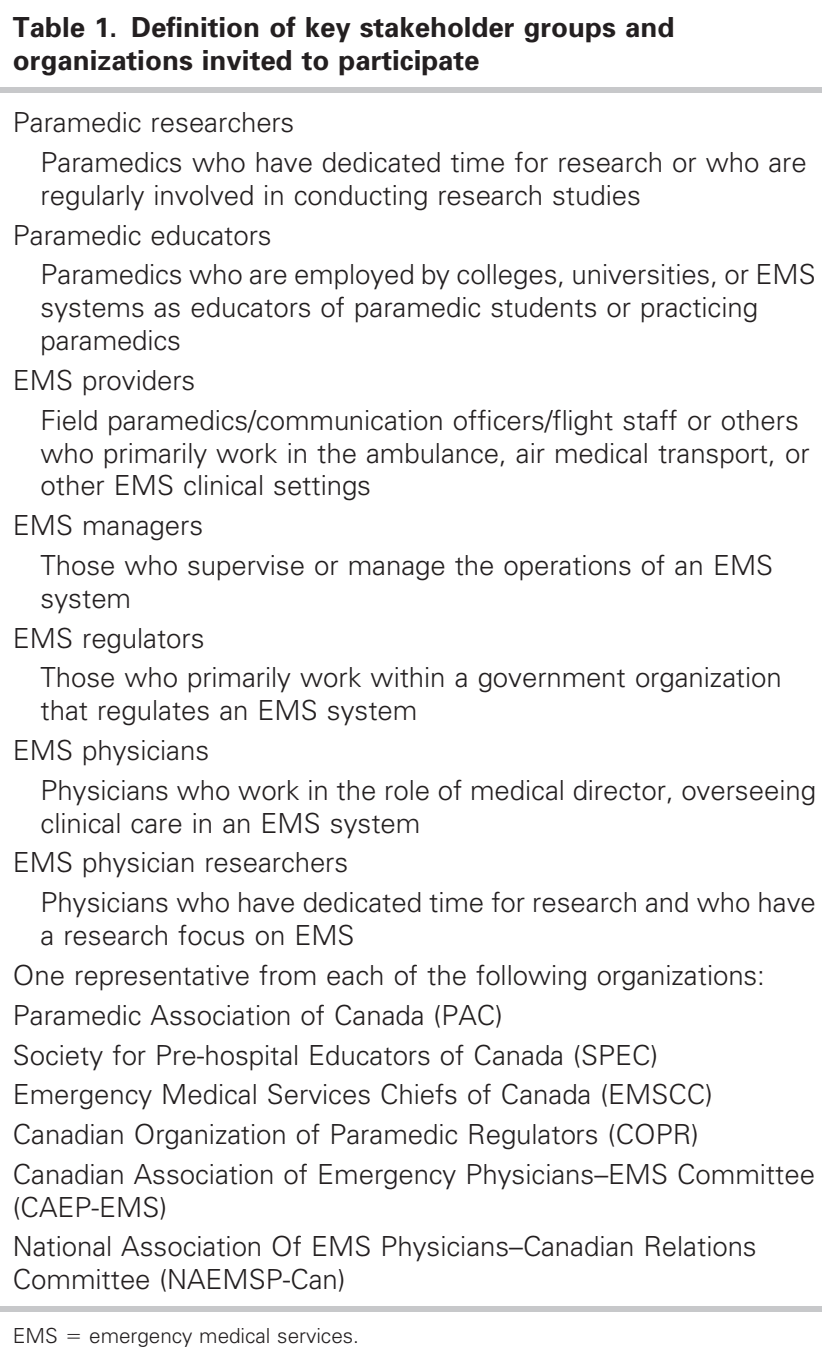

EMS $=$ emergency medical services

conducted over the telephone from a private office and recorded for transcription purposes. A semistructured interview guide was developed by the study team based on discussion with opinion leaders and a review of the relevant existing literature (Appendix). The lead investigator, an experienced qualitative researcher who is not part of the EMS clinical or research communities, conducted all interviews. A professional transcriptionist transcribed the recordings, and the lead investigator reviewed each for accuracy. During transcription, any potential identifying information was removed so that participant identities could not be directly linked to interview data. Interviews were conducted until thematic saturation was reached. Thematic saturation was defined as the point at which no new information was obtained (no variations or exceptions) and there was a "redundancy" in the theme categories in subsequent interviews.

\section{Data analysis}

Two investigators conducted the qualitative data analysis (K.N.D. and B.L.B.). Both independently read each transcript as it was completed in an effort to gain understanding of the issues discussed and develop a preliminary coding scheme. New codes were added to the coding scheme as additional transcripts were reviewed until a final coding scheme was established. All transcripts were then reviewed a second time and coded according to the final scheme. All coding was done by hand, and analytic field notes were kept to ensure consistency. The two investigators compared their independent coding for the first four transcripts and discussed and resolved any areas of divergence in their coding assignments. After that, each investigator coded half of the remaining transcripts. Encoding the information allowed investigators to organize the data to identify and develop themes from within it. ${ }^{4}$

Thematic analysis is a search for themes that appear to be important to the description of a phenomenon. ${ }^{5}$ Connecting or clustering of codes is the process of discovering patterns in the data, ${ }^{6}$ which then become identified as themes. After all transcripts were coded, the two investigators analyzed the data using descriptive thematic analysis methods and identified the major emergent themes. ${ }^{7}$ Descriptive thematic analyses are used to move beyond counting specific words or phrases and instead focus on identifying and describing both implicit and explicit ideas that recur within the content of the data. It is not a prerequisite that all participants express or agree with all of the themes identified; however, major discrepancies in participant opinion, when observed, are reported. The outcome of qualitative descriptive studies is a descriptive summary of the informational contents of data, organized in a way that best represents the data. ${ }^{7}$

\section{RESULTS}

All 20 invited participants consented to participate. Thirteen interviews were conducted between March and May of 2011, at which point, thematic saturation was reached, and it was felt to be unlikely that new information would be obtained from additional interviews. The participants had an average of 14 years of experience (range 7-29 years) in EMS and/or EMS research and were composed of the following: four 
EMS physician researchers, four EMS providers, two EMS physicians, two paramedic educators, and one EMS manager.

Four major themes emerged from analysis of the interview data: 1) the need for additional research education within EMS; 2) the importance of creating an infrastructure to support pan-Canadian research collaboration; 3) addressing the complexities of involving EMS providers in research; and 4) considerations for a national research agenda.

\section{Need for additional research education within EMS}

Participants frequently expressed concerns about the lack of a formalized system of research training for EMS providers and managers. Training in research methods and skills such as critical appraisal are not topics covered in standard paramedic curricula, and their lack may contribute to an underappreciation of the importance of research and inadequate preparation to carry out research protocols while working as EMS providers:

There is...a complete lack of training and understanding at the paramedic level about research. They don't get taught this in [primary care paramedic] schools, ...so they don't know what it's all about. (interview 11, page 4)

I don't think that there is a true appreciation because [paramedic students are] not taught anything about research. (interview 8 page 3)

In addition, although there may be an assumption that EMS physicians have research training and experience, participants indicated that this might not be the case. As a result, EMS physicians may also lack the foundation or support for conducting or applying EMS research. As leaders in EMS, such individuals may not encourage research to be included in the roles of EMS providers and managers. Participants felt that a key component of capacity building was formal education and capability at all levels:

I think part of [a research agenda] needs to be not just education in school but education on research as part of a paramedic system, as part of an EMS system. And that needs to include education for the medical directors. Because the assumption that the physicians have a grounding in research, coming through and coming into a service, is absolutely wrong. (interview 11, page 13)
Paramedics don't have a clear direction... A lot of paramedics have excellent, excellent research ideas, but they don't know where to go with them. (interview 6, pages 3-4)

Mentorship of burgeoning EMS researchers was also suggested as an important consideration for the future.

\section{Importance of creating an infrastructure to support pan- Canadian research collaboration}

The need for and importance of a formal, centralized group to drive EMS research was identified as a key enabler for moving a national research agenda forward. True pan-Canadian collaboration was identified as a requirement, and the current lack of national EMS research-oriented meetings and/or conferences, access to research resources for those working in EMS, and an "engine to drive the work" were commonly mentioned. Linking a centralized group with an existing national organization/association or collaboration of organizations, resonated with the stakeholders:

I mean, one is collaborations are important... We need to keep that collaboration side of things going, and that needs someone to drive it. I mean, if there are universal questions that need to be answered, and we need a way to pool ideas and resources and expertise, we will get better science and better answers. (interview 4, page 6 )

But, really, I think that we can overcome the fragmentation. There's enough information and enough people, sort of a critical mass now to bring it together nationally and say, okay, here's what we have, here's how we should do business, here's what we need, here's what we think. (interview 8 , page 6)

Participants felt that one of the functions of a centralized group could be to improve the research-topractice process through targeted knowledge translation activities, including increased dissemination of information about ongoing work and completed research and guidance and discussion on evaluating and implementing evidence-based guidelines.

\section{Addressing the complexities of involving EMS providers in research}

Participants indicated that several excellent EMS research programs with reputations for conducting 
high-quality investigations exist in Canada. However, they perceived that there are few formal connections with those programs that create and leverage research mentorship opportunities for EMS providers (paramedics, emergency medical dispatchers, and others):

...I would say there are pockets of the country that are doing some really good research. But most of the country, I would say, still is in its infancy. (interview 7 , page 4)

...There are very few EMS research labs, and they are geographically dispersed. So there's not great opportunities to mentor individuals that might be interested... So if there were a specific [funding] stream focused on EMS [within the Canadian Institutes of Health Research], I would strongly advocate that that needs to be a mentoring package. (interview 3 , pages 3,5 )

The need was identified for researchers to involve EMS providers and managers in studies at early stages, such as during hypothesis generation and study design, rather than simply in data collection and study operationalization. However, some participants indicated that it can be complicated to formally involve EMS providers in a study and identified issues related to contracts, time, compensation, and accountability expectations. It was suggested that including EMS research in the strategic and operational mandate of service and provider contracts would enable the engagement of EMS providers in research as part of service delivery without violating contractual agreements.

And right from the beginning as well, we felt that the paramedics not only should be involved with research but should start to be the drivers of the research so they sort of take ownership of that. (interview 4, page 5)

So, for example..., our prehospital system is quite eager, willing, and wanting to help [EMS providers] and collaborate with us doing research. But they kind of have to bend over backwards to do so. And they cannot really clearly call it research because the medic they pull from the road to help us do a research project has to kind of be remanded somehow or be on a medical leave, or they have to invent a work category almost to justify paying that person. They cannot call it research... It's all legal stuff... But you really do get the feeling that there's a will to help... (interview 9, page 6)

\section{Considerations for a national research agenda}

Participants indicated that establishing a research agenda specific to Canada is necessary to improve the conduct and use of EMS research nationally. Participants often mentioned how diverse EMS care and delivery are in Canada when urban versus rural settings and our varied patient population are considered:

I live and work in an urban setting in relatively southern Canada. But what about the more rural Canadian EMS centres and what challenges they are facing? ...because it's a Canadian research agenda that we should be examining and asking our colleagues who work in a more northern and rural environment. (interview 5, pages 8-9)

Some participants felt that research conducted in Canada or issues relevant to the Canadian setting were often not well represented in education resources, such as textbooks and training materials, which are often written in the United States:

...Having Canadian-based research in EMS would actually be very valuable since as a Canadianeducated paramedic, all we ever see from textbooks, it all comes out of the US... So having Canadian-based research would actually benefit Canadians themselves because it would be more tailored to our reality. (interview 10, page 10)

Participants strongly expressed the importance of ensuring true national representation as an EMS research agenda is developed. Some indicated that certain issues would be important nationally, whereas others would be more or less important at a local system level. Participants also suggested that the research agenda should not prioritize specific research questions but rather identify general topics that required further study:

...Is it important for Canada to move towards a national research agenda? ...Yes, yes, absolutely... I mean, if there are universal questions that need to be answered, and we can pool ideas and resources and expertise, we will get better science and better answers. (interview 4 , page 6 ) 
So, essentially, we need a bunch of people that come together to think about all the issues that we are faced with in the EMS system. List them and try to see what kind of quick impact we can have and start to make some small victories. (interview 9, pages 8-9)

Finally, participants emphasized the importance of ensuring that recommendations for change collected through this process are acted on to improve Canadian EMS research.

\section{DISCUSSION}

We conducted a qualitative study, the purpose of which was to understand the current state of EMS research through the barriers and opportunities perceived by key stakeholders in the Canadian system and identify the recommendations this group had for moving forward. Four themes pertaining to the Canadian EMS Research Agenda were identified: 1) the need for additional research education within EMS; 2) the importance of creating an infrastructure to support pan-Canadian research collaboration; 3) addressing the complexities of involving EMS providers in research; and 4) considerations for a national research agenda. These themes will be important for the next two phases of the Canadian EMS research agenda project. ${ }^{2}$

This is not the first time work has been performed to develop a large-scale research agenda to guide EMS research, ${ }^{8,9}$ nor is creating a national research agenda unique to EMS. ${ }^{10-12}$ However, this study was designed as a baseline starting point for a larger consensus-driven methodology and provides important direction for a subsequent roundtable discussion and Delphi survey.

The main strength of beginning a broad initiative such as a national research agenda with qualitative research is the inherent subjectivity of this research methodology, which allows for aggregation of multiple perspectives. ${ }^{13}$ In the Canadian setting, EMS research is currently conducted in pockets throughout the country, so the investigators felt that the use of a qualitative methodology to explore perceptions and experiences was an important first step to building a comprehensive national EMS research agenda. To our knowledge, other EMS research agendas have not used such an approach. Other strengths of our study include a rigorous approach to conducting the qualitative data collection, including the interviews and analysis being conducted by a researcher without ties or affiliations to the EMS clinical or research community and a focus on analyzing emerging themes grounded in the data, in contrast to following a predefined framework.

This study has limitations that should be considered. The sample size was small; however, it was clear that thematic saturation had been reached, so we are confident that it can be considered representative of the targeted stakeholder population. The study sample was selected from a larger group of individuals identified as being actively involved in EMS research. As a result, the opinions of EMS providers and administrators not currently involved in EMS research were not captured in this study. Two stakeholder groups were not included in the study sample: paramedic researchers and EMS regulators. The paramedic researcher group was likely adequately represented by paramedic participants categorized into other stakeholder groups but who had research experience. The results of the question on top future research priorities is not reported here due to the poor construction of the question, which caused participants to have difficulty directly answering it.

\section{CONCLUSION}

This hypothesis-generating study reveals key areas regarding EMS research in Canada and through the guidance it provides is a first step in the development of a comprehensive national research agenda. Our intention is to collate the identified themes with the results of a larger roundtable discussion and Delphi survey and, in doing so, guide development of a Canadian national EMS research agenda.

Acknowledgements: We thank Mary Ann Martell, Dalhousie University, for transcription work and all the study participants for their contributions.

Competing interests: The Canadian National EMS Research Agenda project was funded by the EMS Chiefs of Canada, the Paramedic Association, the Calgary EMS Foundation, the Canadian Institutes of Health Research (funding number KPE112496), Canadian Police Research Centre (funding number W7714-125453) and the Nova Scotia Health Research Foundation (funding number PSO-REDI-2010-7142).

\section{REFERENCES}

1. Emergency Medical Services Chiefs of Canada. The future of EMS in Canada: defining the new road ahead. 2006. Available at: www.emscc.ca/docs/EMS-Strategy-Document.pdf (accessed April 13, 2012). 
2. Jensen JL, Blanchard IE, Bigham BL, et al. Methodology for the development of a Canadian national EMS research agenda. BMC Emerg Med 2011;11:15, doi:10.1186/1471227X-11-15.

3. Greenhalgh T, Russell J, Swinglehurst D. Narrative methods in quality improvement research. Qual Saf Health Care 2005;14:443-9, doi:10.1136/qshc.2005.014712.

4. Daly J, Kellehear A, Gliksman M. The public health researcher: a methodological approach. Melbourne (Australia): Oxford University Press; 1997.

5. Crabtree B, Miller W. A template approach to text analysis: developing and using codebooks. In: Crabtree B, Miller W, editors. Doing qualitative research. Newbury Park (CA): Sage; 1999. p. 163-77.

6. Fereday J, Muir-Cochrane E. Demonstrating rigor using thematic analysis: a hybrid approach of inductive and deductive coding and theme development. Int 7 Qual Methods 2006;5(1):80-92.

7. Sandelowski M. Whatever happened to qualitative description? Res Nurs Health 2000;23:334-40, doi:10.1002/1098240X(200008)23:4<334::AID-NUR9>3.0.CO;2-G.

8. Sayre MR, White LJ, Brown LH, et al. National EMS research agenda. Prehosp Emerg Care 2002;6(3 Suppl):S1-43. doi: $10.3109 / 10903120209102681$.

9. Tippett V, Clark M, Woods S, et al. Towards a national research agenda for the ambulance and pre-hospital sector in Australia. F Emerg Prim Health Care 2003;1(1-2):990007.

10. Valiga TM, Ironside PM. Crafting a national agenda for nursing education research. 7 Nurs Educ 2012;51:3-6, doi: 10.3928/01484834-20111213-01.

11. Lenaway D, Halverson P, Sotnikov S, et al. Public health systems research: setting a national agenda. Am 7 Public Health 2006;96:410-3, doi:10.2105/AJPH.2004.046037.

12. Schroedel JG, Watson D, Ashmore DH. A national research agenda for the postsecondary education of deaf and hard of hearing students: a road map for the future. Am Ann Deaf 2003;148:67-73, doi:10.1353/aad.2003.0014.

13. Given LM, editor. The Sage Encyclopedia of Qualitative Research Methods - Vol.2. Thousand Oaks (CA): Sage; 2008.

\section{APPENDIX: SEMISTRUCTURED INTERVIEW GUIDE}

The interviewer will describe the nature of the larger project and purpose of these key informant interviews.
Declaration of audio-taping and completion of informed consent are to be completed before any discussion begins. (Possible probes listed in italics)

1. You have been asked to be part of this project because of your involvement with EMS research in Canada. Can you tell me about how you are involved?

- Current role

- Organization

- How they got involved in the first place

- Amount of time spent on research

2. Can you tell me more about the type of prehospital research you do?

3. What do you enjoy about doing EMS research?

- Looking for drivers here

4. Do you think it is easy or difficult to do EMS research in Canada?

- Probe recognition of EMS/prebospital research in Canada

- Do you think it is different in other countries?

5. What types of things facilitate your research?

- i.e., good collaboration, good databases, good funding?

6. Do you encounter any difficulties in doing your research here in Canada?

- Probe reasons for each "barrier"- -system issues, financial, etc.

7. What are your thoughts on funding for EMS research here in Canada?

8. Do you think it is important to focus on building a Canadian EMS research agenda?

9. If this group was going to work to improve EMS research in Canada, what do you think their top three areas of focus should be?

10. Is there anything else you would like to tell me about EMS research in Canada? 